\title{
PENGARUH KEPUASAN DAN NILAI YANG DIPERSEPSIKAN NASABAH TERHADAP MINAT MENGGUNAKAN BAITUL MAAL WA TAMWIL (BMT) DALAM PERSEPSI MASYARAKAT
}

\author{
Yusril Ihza Mahendra'), Slamet Asih Muliya2), Dwi Fatmawati'3) \\ 1),2),3) IAIN Pekalongan \\ 1)yusrilihza1012@gmail.com, 2) asihmuliya86@gmail.com, 3)
}

\begin{abstract}
Abstrak: Pengaruh ialah daya yang muncul atau timbul dari sesuatu (orang atau benda) yang ikut membentuk watak, kepercayaan, atau perbuatan seseorang. Kepuasan didefinisikan sebagai perasaan puas seseorang yang muncul setelah menggunakan suatu produk atau menikmati layanan suatu perusahaan yang kemudian membandingkannya antara persepsi dengan kinerja suatu produk dan harapan-harapannya. Pengaruh kepuasan seseorang terhadap suatu produk atau jasa akan menghantarkan nilai yang nantinya akan dipersepsikan seseorang dalam wujud bersedia membeli atau menggunakan barang serta jasa yang ditawarkan. Sedangkan Baitul Maal Wa Tamwil (BMT) sendiri adalah lembaga keuangan mikro yang dioperasikan menggunakan prinsip-prinsip syariah.
\end{abstract}

Kata Kunci: Pengaruh, Kepuasan, BMT

\begin{abstract}
Influence is a power that arises or arises from something (person or thing) which contributes to a person's character, belief, or action. Satisfaction is defined as a person's feeling of satisfaction that arises after using a product or enjoying a company's services which then compares the perception to the performance of a product and its expectations. The effect of one's satisfaction on a product or service will deliver value that someone will perceive in the form of being willing to buy or use the goods and services offered. Meanwhile, Baitul Maal Wa Tamwil (BMT) is a microfinance institution that operates using sharia principles.
\end{abstract}

Keyword: Influence, Satisfaction, BMT

\section{PENDAHULUAN}

Sektor perbankan telah berkembang dan tumbuh sangat pesat juga mendominasi kegiatan perekonomian di Indonesia. Kegiatan pada sektor perbankan sangat mempengaruhi kemajuan suatu Negara dalam bidang perekonomian. Salah satunya yaitu berkembangannya lembaga keuangan mikro. Munculnya lembaga keuangan syariah ataupun unit usaha syari'ah khususnya di Indonesia dikarenakan jumlah mayoritas masyarakat atau penduduk Indonesia banyak yang menganut agama Islam. Adanya lembaga keuangan syari'ah serta unit usaha syari'ah sangat diharapkan bisa menjalankan kegiatan operasionalnya sesuai dengan kondisi dan situasi masyarakat secara sempit juga negara secara luas pada saat ini, baik dibidang ekonomi, politik, maupun sosialdan budaya masyarakat Indonesia. Sejalan dengan 
berjalannya waktu, kegiatan peredaran lembaga keuangan syari'ah menjadi semakin populer di masyarakat, salah satunya yaitu Baitul Mal wa Tamwil (BMT) yang muncul sebagai Usaha Syari'ah yang diharapkan bisa memadukan nilai rohani dengan idealisme usaha yang harmonis diantara keduanya. Hal tersebut yang dianggap menjadi sebuah keunggulan yang dimiliki oleh BMT dibandingkan dengan Unit Usaha Konvensional lainnya.

Kepuasan nasabah terhadap lembaga keuangan syariah akan muncul jika di lembaga tersebut mampu memberikan pelayanan, kualitas, dan mutu yang baik sehingga mewujudkan nilai nasabah yang baik pula. Ketika nasabah merasa puas, maka nilai yang muncul pun akan baik, dan sebaliknya jika nasabah merasa tidak puas, maka nilai yang muncul akan tidak baik. Dengan pelayanan, kualitas, dan mutu yang baik dan tidak berbelit akan membuat nasabah mempersepsikan bahwa dengan memilih dan menggunakan Baitul Maal Wa Tamwil (BMT) adalah hal yang sudah tepat. Karena penilaian nasabah akan menentukan persepsi dan keputusan yang akan diambilnya, dan hal tersebut berawal dari pihak manajemen Baitul Maal Wa Tamwil (BMT) itu sendiri.

\section{METODE PENELITIAN}

Jenis Penelitian ini menggunakan jenis penelitian lapangan (field research) maksudnya data dalam penelitian ini didapat dari kajian di lapangan menggunakan cara pengamatan, pencatatan dan pengumpulan berbagai informasi dan data yang akan diperoleh di lapangan. Penelitian ini menggunakan jenis penelitian lapangan karena bentuk pengumpulan data dan informasi yang ditemukan dilokasi penelitian di Baitul Maal Wa Tamwil (BMT) Kecamatan Bojong, Kabupaten Pekalongan.

Adapun dalam penelitian ini menggunakan metode kualitatif, yang mempunyai maksud untuk memahami fenomena tentang apa saja hal yang dialami oleh subjek penelitian menggunakan teknik deskripsi dalam bentuk bahasa dan kata-kata. Alasan peneliti mengambil metode kualitatif dalam penelitian adalah dari ciri-ciri tertentu yang terdapat dalam penelitian, dan metode ini dapat menyajikan secara langsung hakikat hubungan antara peneliti dengan responden. Dalam penelitian ini, penulis mencari data, meneliti, mengkaji dan melakukan observasi. Nantinya informasi yang didapatkan berdasarkan hasil wawancara digunakan untuk memahami Pengaruh Kepuasan dan Nilai yang Dipersepsikan Nasabah Terhadap Minat Menggunakan Baitul Maal Wa Tamwil (BMT) dalam Persepsi Masyarakat. 


\section{KAJIAN TEORI}

\section{Pengertian Baitul Maal Wa Tamwil (BMT)}

Baitul Maal Wa Tamwil (BMT) adalah lembaga keuangan mikro yang dioperasikan menggunakan prinsip-prinsip syariah. BMT terdiri dari dua kata yaitu Baitul maal yang berarti rumah dana dan Baitultamwil yang berarti rumah usaha. Dari pengertian tersebut bisa ditarik definisi Baitul Maal Wa Tamwil (BMT) adalah organisasi bisnis yang berperan sosial yang berfungsi sebagai menghimpun dan menyalurkan dana kepada anggotanya dan biasanya beroperasi dalam skala mikro.

\section{Kepuasan}

Kepuasan merupakan rasa senang atau juga kecewa yang diperoleh seseorang karena membedakan antara kinerja (atau hasil) dari produk yang dipersepsikan dan ekspektasinya ${ }^{1}$. Seseorang akan merasa puas atau tidak puas, bergantung terhadap kinerja produk. Jika kinerja dirasa lebih rendah daripada ekspektasi, maka seseorang bersangkutan akan merasakan ketidakpuasan. Sedangkan jika kinerja dirasa sama dengan ekspektasi, maka ia akan merasa puas. Kemudian jika suatu kinerja melampaui ekspektasi, maka orang tersebut akan merasakan rasa sangat puas atau bahkan bahagia.

Pengaruh yang mungkin terjadi akibat dari rasa kepuasan pada seseorang antara lain yaitu akan membeli kembali produk yang sama, merekomendasikan produk kepada orang lain, bersedia membayar lebih, dan akan memberikan masukan positif kepada pihak pemilik produk.

\section{Nilai}

Nilai merupakan suatu tatanan yang menjadi panduan bagi individu guna memilih dan juga menimbang alternatif keputusan di dalam kondisi dan situasi sosial tertentu atas kualitas yang ditawarkan relatif lebih tinggi dari pesaing yang akan berpengaruh terhadap tingkat loyalitas konsumen, jika persepsi nilai yang dirasakan oleh seseorang semakin tinggi, maka kemungkinan terjadinya hubungan (transaksi) akan semakin besar (Tjiptono, 2007) ${ }^{2}$. Dalam Rangkuti (2006) menjelaskan nilai sebagai pengkajian yang secara menyeluruh tentang manfaat suatu produk, yang didasarkan oleh persepsi seseorang atas apa yang telah diterima oleh orang tersebut dan yang telah diberikan oleh produk tersebut.

${ }^{1}$ Malayu, Hasibuan. 2009. Manajemen Dasar Pengertian dan Masalah. Jakarta: PT Bumi Aksara.

${ }^{2}$ Sofjan Assauri. 2013. Strategi Marketing: Sustaining Lifetime Customer Value. Jakarta: PT Raja Grafindo Persada. 
Dimensi persepsi nilai yang penting terdiri dari aspek nilai emosional yang berwujud untuk membuat konsumen merasa puas dan senang serta ingin kembali mengkonsumsi produk, lalu nilai sosial yang berwujud menciptakan rasa bangga pada konsumen atas suatu produk, dan juga nilai kualitas yang berwujud manfaat yang diperoleh dari produk.

\section{Persepsi}

Menurut Sunyoto, persepsi ialah menjadi proses dimana orang memilih, mengatur serta menafsirkan informasi masukan, sehingga menciptakan pandangan bermakna di dunia. Penafsiran suatu peristiwa yang berdasar pada pengalaman masa lalu seseorang melibatkan sebuah persepsi juga. Sarlito WS berpendapat bahwasannya persepsi merupakan kemampuan yang dimiliki oleh seseorang dalam menjalankan observasi, yang terdiri dari kemampuan untuk mengelompokkan dan memfokuskan. Oleh karena nya, walaupun objeknya sama, seseorang bisa memiliki persepsi yang berbeda. Hal tersebut sangat mungkin akibat dari perbedaan di dalam sistem nilai dan ciri kepribadian.

\section{Minat Terhadap Baitul Maal Wa Tamwil (BMT)}

Kecenderungan hati untuk menjadi nasabah di Baitul Maal Wa Tamwil (BMT), jika seseorang nasabah memang benar ingin menabung atau melakukan simpanan dan juga pembiayaan maka orang tersebut akan mencari informasi mengenai BMT. Dalam rangka menaikkan minat masyarakat untuk menjadi nasabah di lembaga syariah, ada beberapa hal yang dapat diperhatikan, aspekitu mencakup tangible, responsively, assurance, reality dan emphaty, sehingga nasabah akan meningkatkan minatnya untuk memakai ulang produk yang sudah mereka gunakan. Pelayanan yaitu setiap kegiatan atau tindakan yang bisa ditawarkan oleh suatu pihak pada pihak lain, yang pada dasarnya tidak mengakibatkan kepemilikan apapun, dan tidak berwujud dimana pelayanan adalah tindakan produsen dalam rangka memenuhi keinginan konsumen dan kebutuhan demi tercapaianyaminat beli ulang kepuasan pada konsumen tersebut.

Kualitas pelayanan sangat diperlukan oleh lembaga syariah guna menarik minat nasabah, hal tersebut karena kualitas dari pelayanan adalah suatu faktor yang dapat menentukan keberhasilan dalam sebuah usaha. Biasanya nasabah lembaga syariah memiliki perasaan senang jika dilayani dengan baik oleh petugas lembaga syariah seperti sikapramah tamah petugas, kecepatan dalam pelayanan pembiayaan, seperti 
halnya tidak mempersulit syarat pengajuan dalam pembiayaan, maka hal tersebut dijadikan sarana bagi lembaga untuk menarik minat nasabah.

\section{PEMBAHASAN}

Dari penelitian ini dapat diperoleh jumlah keseluruhan hasil wawancara dan observasi yang telah dilakukan sebanyak 56 responden dalam penelitian mengenai Pengaruh Kepuasan dan Nilai yang Dipersepsikan Nasabah Terhadap Minat Menggunakan Baitul Maal Wa Tamwil (BMT) dalam Persepsi Masyarakat, sebagai berikut:

Daftar Responden

\begin{tabular}{|c|c|c|c|c|}
\hline No & Nama & Jenis Kelamin & Umur & Status \\
\hline 1 & Salsabila & $\mathrm{P}$ & 22 & Pelajar \\
\hline 2 & Fitriyani & $\mathrm{P}$ & 20 & Pelajar \\
\hline 3 & Arief Rahman & $\mathrm{L}$ & 23 & Bekerja \\
\hline 4 & Galiya & $\mathrm{P}$ & 20 & Pelajar \\
\hline 5 & Siti Khumaeroh & $\mathrm{P}$ & 21 & Bekerja \\
\hline 6 & Uswatun Khasanah & $\mathrm{P}$ & 17 & Pelajar \\
\hline 7 & Dina & $\mathrm{P}$ & 20 & Pelajar \\
\hline 8 & Dwi Putri & $\mathrm{P}$ & 20 & Pelajar \\
\hline 9 & Dian S & $P$ & 20 & Pelajar \\
\hline 10 & Nafilatul Nadia & $\mathrm{P}$ & 20 & Bekerja \\
\hline 11 & Ledi Maya Diana & $\mathrm{P}$ & 20 & Pelajar \\
\hline 12 & M. Fani Saifullah & $\mathrm{L}$ & 21 & Pelajar \\
\hline 13 & Gina Anggraini & $P$ & 20 & Pelajar \\
\hline 14 & Sylviana Salsabila & $\mathrm{P}$ & 20 & Pelajar \\
\hline 15 & Indah Kurnia & $\mathrm{P}$ & 20 & Bekerja \\
\hline 16 & Ify & $P$ & 20 & Pelajar \\
\hline 17 & Nur Azizah & $\mathrm{P}$ & 20 & Pelajar \\
\hline 18 & Afi Sukma Ningsih & $P$ & 22 & Bekerja \\
\hline 19 & Nur Imadudin & $\mathrm{L}$ & 24 & Bekerja \\
\hline 20 & Azizan Khakim & $\mathrm{L}$ & 26 & Bekerja \\
\hline 21 & Himatul & $\mathrm{P}$ & 19 & Pelajar \\
\hline 22 & Nur Khasanah & $P$ & 25 & Bekerja \\
\hline
\end{tabular}




\begin{tabular}{|c|c|c|c|c|}
\hline 23 & Eviana Citra Devi & $\mathrm{P}$ & 20 & Pelajar \\
\hline 24 & Diah Ayu & $\mathrm{P}$ & 21 & Bekerja \\
\hline 25 & Winda Widya & $\mathrm{P}$ & 21 & Pelajar \\
\hline 26 & Nella K & $\mathrm{P}$ & 20 & Pelajar \\
\hline 27 & Khaerudin Hidayat & $\mathrm{L}$ & 22 & Pelajar \\
\hline 28 & Dewi Asmi Safira & $\mathrm{P}$ & 20 & Pelajar \\
\hline 29 & Ghina Jazilla & $\mathrm{P}$ & 22 & Pelajar \\
\hline 30 & Aulia & $\mathrm{P}$ & 20 & Pelajar \\
\hline 31 & M. Miftakhuddin & $\mathrm{L}$ & 20 & Pelajar \\
\hline 32 & Galuh & $\mathrm{L}$ & 22 & Pelajar \\
\hline 33 & Salisa & $\mathrm{P}$ & 21 & Pelajar \\
\hline 34 & Isnaini Setianingrum & $\mathrm{P}$ & 23 & Bekerja \\
\hline 35 & Naila Rizqiyana & $\mathrm{P}$ & 20 & Pelajar \\
\hline 36 & Afrina Nur Imas & $P$ & 20 & Pelajar \\
\hline 37 & Nabila & $\mathrm{P}$ & 22 & Bekerja \\
\hline 38 & Moh. Ibad Batslakh & $\mathrm{L}$ & 24 & Bekerja \\
\hline 39 & Adi M & $\mathrm{L}$ & 22 & Pelajar \\
\hline 40 & Falen & $\mathrm{P}$ & 21 & Bekerja \\
\hline 41 & Dian Purwandari & $P$ & 27 & Bekerja \\
\hline 42 & Gading & $\mathrm{L}$ & 23 & Bekerja \\
\hline 43 & Faqih & $\mathrm{L}$ & 24 & Bekerja \\
\hline 44 & Khairul Ulum & $\mathrm{L}$ & 23 & Bekerja \\
\hline 45 & Nurul & $\mathrm{P}$ & 23 & Bekerja \\
\hline 46 & Erika Damayanti & $\mathrm{P}$ & 21 & Pelajar \\
\hline 47 & Agus Abdul Halim & $\mathrm{L}$ & 22 & Bekerja \\
\hline 48 & Muhamad Ardiyansyah & $\mathrm{L}$ & 20 & Pelajar \\
\hline 49 & Minati Nabila & $\mathrm{P}$ & 20 & Pelajar \\
\hline 50 & M. Abdul Ghofur & $\mathrm{L}$ & 23 & Bekerja \\
\hline 51 & Sukma Lestari & $\mathrm{P}$ & 21 & Bekerja \\
\hline 52 & Misbakhul Munir & $\mathrm{L}$ & 22 & Bekerja \\
\hline 53 & Esti & $\mathrm{P}$ & 21 & Bekerja \\
\hline 54 & Kholisotul M & $\mathrm{P}$ & 20 & Pelajar \\
\hline
\end{tabular}




\begin{tabular}{|c|c|c|c|c|}
\hline 55 & Indah Kurnia & P & 23 & Bekerja \\
\hline 56 & Amin Marzuki & L & 21 & Pelajar \\
\hline
\end{tabular}

Tabel 1.1 Sumber: Data Primer (Wawancara, Observasi, 2021)

Identitas Responden Menurut Jenis Kelamin

\begin{tabular}{|c|c|}
\hline Jenis Kelamin & Jumlah Responden \\
\hline Laki-laki & 17 \\
\hline Perempuan & 39 \\
\hline Jumlah Total & 56 \\
\hline
\end{tabular}

Tabel 1.2 Sumber: Data Primer (Wawancara, Observasi, 2021)

Tabel 1.2 menunjukkan bahwa keadaan responden menurut jenis kelamin terdiri sebanyak 56 orang, yaitu 17 orang Laki-laki dan 39 orang Perempuan. Dari hasil tersebut bisa diketahui bahwa dari hasil pengamatan masyarakat Kecamatan Bojong Kabupaten Pekalongan yang berjenis kelamin Perempuan lebih antusias untuk diwawancarai tentang Pengaruh Kepuasan dan Nilai yang Dipersepsikan Nasabah Terhadap Minat Menggunakan Baitul Maal Wa Tamwil (BMT) dalam Persepsi Masyarakat.

Identitas Responden Menurut Usia

\begin{tabular}{|c|c|}
\hline Usia & Jumlah Responden \\
\hline Usia dibawah 20 tahun & 2 \\
\hline Usia 20 tahun-30 tahun & 54 \\
\hline Jumlah Total & 56 \\
\hline
\end{tabular}

Tabel 1.3 Sumber: Data Primer (Wawancara, Observasi, 2021)

Berdasarkan Tabel 1.3 diatas menunjukkan bahwa keadaan responden menurut usia terdiri dari sebanyak 2 orang memiliki usia dibawah 20 tahun, sebanyak 54 orang memiliki usia dari rentang 20 tahun-30 tahun. Dengan demikian dapat diketahui bahwa rentang usia antara 20 tahun-30 tahun menjadi usia yang produktif bagi masyarakat untuk menggunakan Baitul Maal Wa Tamwil (BMT) karena dilihat mereka mempunyai antusiasme yang tinggi untuk mengetahui tentang Baitul Maal Wa Tamwil (BMT).

Identitas Responden Menurut Status 


\begin{tabular}{|c|c|}
\hline Status & Jumlah Responden \\
\hline Pelajar & 32 \\
\hline Bekerja & 24 \\
\hline Jumlah Total & 56 \\
\hline
\end{tabular}

Tabel 1.4 Sumber: Data Primer (Wawancara, Observasi, 2021)

Berdasarkan Tabel 1.4 menunjukkan bahwa identitas responden menurut status terdiri dari sebanyak 32 responden adalah berstatus sebagai pelajar sedangkan 24 responden lainnya berstatus sebagai pekerja. Dengan demikian, dapat diketahui bahwasannya usia jenjang pelajar yang masih memiliki keingintahuan yang tinggi terhadap Baitul Maal Wa Tamwil (BMT) dan juga disisi lain responden yang sudah bekerja juga tidak menutup kemungkinan untuk memahami lebih detail tentang Baitul Maal Wa Tamwil (BMT).

Kepuasan Nasabah Terhadap Baitul Maal Wa Tamwil (BMT)

\begin{tabular}{|c|c|c|}
\hline Jawaban & Jumlah & $\%$ \\
\hline Puas & 45 & 80 \\
\hline Kurang Puas & 11 & 20 \\
\hline Total & 56 & 100 \\
\hline
\end{tabular}

Tabel 1.5 Sumber: Data Primer (Wawancara, Observasi, 2021)

Berdasarkan Tabel 1.5 diatas menunjukan bahwa Kepuasan Nasabah Terhadap Baitul Maal Wa Tamwil (BMT) sebanyak 45 orang atau $80 \%$ responden merasa puas terhadap Baitul Maal Wa Tamwil (BMT), dan sebanyak 11 orang atau 20\% responden merasa kurang puas terhadap Baitul Maal Wa Tamwil (BMT). Dengan demikian dapat diketahui bahwasannya masyarakat di Kecamatan Bojong Kabupaten Pekalongan lebih didominasi oleh masyarakat yang merasa puas terhadap Baitul Maal Wa Tamwil (BMT). Beberapa ketidakpuasan responden lainnya terhadap Baitul Maal Wa Tamwil (BMT) dikarenakan masyarakat belum mencoba menggunakan Baitul Maal Wa Tamwil (BMT).

Nilai yang diberikan Nasabah Terhadap Baitul Maal Wa Tamwil (BMT)

\begin{tabular}{|c|c|c|}
\hline Jawaban & Jumlah & $\%$ \\
\hline Baik & 34 & 60 \\
\hline Kurang Baik & 22 & 40 \\
\hline Total & 56 & 100 \\
\hline
\end{tabular}

Tabel 1.6 Sumber: Data Primer (Wawancara, Observasi, 2021) 
Berdasarkan Tabel 1.6 diatas menunjukan bahwa sebanyak 34 orang atau $60 \%$ responden memberikan nilai yang baik terhadap Baitul Maal Wa Tamwil (BMT), dan sebanyak 22 orang atau 40\% responden memberikan nilai yang kurang baik terhadap Baitul Maal Wa Tamwil (BMT). Dengan demikian dapat diketahui bahwasannya masyarakat di Kecamatan Bojong Kabupaten Pekalongan lebih banyak yang memberikan nilai baik terhadap Baitul Maal Wa Tamwil (BMT), dan ada sebagian responden yang memberikan nilai kurang baik terhadap Baitul Maal Wa Tamwil (BMT), hal ini kemungkinan bisa terjadi karena keterbatasan pengetahuan terkait Baitul Maal Wa Tamwil (BMT) dan karena masyarakatnya yang berpendidikan rendah.

Minat Terhadap Baitul Maal Wa Tamwil (BMT)

\begin{tabular}{|c|c|c|}
\hline Jawaban & Jumlah & $\%$ \\
\hline Ya & 28 & 50 \\
\hline Tidak & 28 & 50 \\
\hline Total & 56 & 100 \\
\hline
\end{tabular}

Tabel 1.7 Sumber: Data Primer (Wawancara, Observasi, 2021)

Berdasarkan Tabel 1.7 diatas menunjukan minat masyarakat terhadap Baitul Maal Wa Tamwil (BMT) bahwa sebanyak 28 orang atau 50\% responden berkeinginan untuk menggunakan atau mempercayai Baitul Maal Wa Tamwil (BMT), dan sebanyak 28 orang atau $50 \%$ responden tidak berkeinginan menggunakan atau mempercayai Baitul Maal Wa Tamwil (BMT). Berdasarkan Tabel 1.4 diatas dapat disimpulkan bahwa jumlah prosentase responden atau masyarakat yang minat terhadap Baitul Maal Wa Tamwil (BMT) setara dengan jumlah prosentase responden atau masyarakat yang tidak minat terhadap Baitul Maal Wa Tamwil (BMT). Artinya sebagian besar masyarakat di Kecamatan Bojong Kabupaten Pekalongan berminat menggunakan Baitul Maal Wa Tamwil (BMT), dan sebagian lainnya yang tidak mau menggunakannya terjadi karena mungkin mereka sudah menggunakan Bank atau Lembaga lainnya.

Berdasarkan dari hasil observasi dan wawancara yang didapatkan dari responden, Interpretasi tentang pengaruh kepuasan dan nilai yang dipersepsikan nasabah dapat ditarik benang merah bahwa hal tersebut menjadi faktor pemicu utama yang memengaruhi terhadap minat menggunakan Baitul Maal Wa Tamwil (BMT) dalam persepsi masyarakat. Hal ini dikarenakan pengaruh kepuasan dan nilai yang dipersepsikan nasabah dapat memberikan pengaruh pada minat menggunakan Baitul Maal Wa Tamwil (BMT). Artinya semakin tinggi orang yang mengerti dan memiliki pengetahuan tentang Baitul Maal Wa Tamwil (BMT) lalu 
mempersepsikannya dengan nilai yang baik secara keseluruhan baik dari pelayanan, kualitas, mutu produk maupun keamanan segala produknya akan semakin tinggi pula keinginan mereka untuk menggunakan Baitul Maal Wa Tamwil (BMT) dan semakin tinggi pula kemungkinan nasabah merasa puas. Hal tersebut dibuktikan dengan hasil penelitian diatas bahwa masyarakat mayoritas memahami tentang Baitul Maal Wa Tamwil (BMT), tentang nilai-nilai dan prinsip syariah yang digunakan dan diterapkan dalam operasinya, seperti menghindari praktik Riba atau bunga dan tentang keberadaan Baitul Maal Wa Tamwil (BMT) yang berperan untuk menghindarkan masyarakat dari praktik ekonomi non syariah yang marak. Tapi yang sangat disayangkan, dari pengetahuan yang mereka miliki terlihat masih belum memahami betul tentang produk-produk yang dimiliki oleh Baitul Maal Wa Tamwil (BMT) sehingga mempengaruhi minat masyarakat untuk menggunakannya. Dapat dilihat bawa minat menggunakan dan mempercayai Baitul Maal Wa Tamwil (BMT) setara antara masyarakat yang berkeinginan dan juga masyarakat yang tidak berkeinginan.

Persepsi Masyarakat tentang Baitul Maal Wa Tamwil (BMT) khususnya mengenai mutu produk dan keamanan simpanan di Baitul Maal Wa Tamwil (BMT) sangat penting dan menjadi faktor utama yang memicu masyarakat ingin menjadi nasabah atau pengguna produk-produk di Baitul Maal Wa Tamwil (BMT). Mengingat banyaknya lembaga keungan di era ini yang semakin berkembang dan juga saling mengunggulkan prinsip dan nilai syariah pada masing-masing lembaga tersebut, karena memang prinsip dan nilai syariah sedang menjadi trend dan banyak diminati oleh masyarakat, hal tersebut dikarenakan lembaga yang menggunakan prinsip atau pun nilai syariah dianggap lebih terpercaya dan aman.

\section{PENUTUP}

\section{Simpulan}

Berdasarkan dari hasil observasi dan wawancara yang didapatkan dari responden, Interpretasi tentang pengaruh kepuasan dan nilai yang dipersepsikan nasabah dapat ditarik benang merah bahwa hal tersebut menjadi faktor pemicu utama yang memengaruhi terhadap minat menggunakan Baitul Maal Wa Tamwil (BMT) dalam persepsi masyarakat. Hal ini dikarenakan pengaruh kepuasan dan nilai yang dipersepsikan nasabah dapat memberikan pengaruh pada minat menggunakan Baitul Maal Wa Tamwil (BMT). Artinya semakin tinggi orang yang mengerti dan memiliki pengetahuan tentang Baitul Maal Wa Tamwil (BMT) lalu mempersepsikannya dengan nilai yang baik secara keseluruhan baik dari pelayanan, kualitas, mutu produk maupun keamanan segala produknya akan semakin tinggi pula keinginan 
mereka untuk menggunakan Baitul Maal Wa Tamwil (BMT) dan semakin tinggi pula kemungkinan nasabah merasa puas.

\section{Saran}

Berdasar pada uraian data lapangan dan pembahasan, bahwa hasil tersebut dapat dijadikan pelajaran khususnya menjadi agenda bagi pihak lembaga Baitul Maal Wa Tamwil (BMT) untuk memberikan penyuluhan atau sosialisai terhadap masyarakat tentang Baitul Maal Wa Tamwil (BMT) secara keseluruhan mulai dari tujuan, maksud, visi misi, kualitas pelayanan, mutu produk, keamanan produknya, ataupun hal lain yang menyangkut tentang Baitul Maal Wa Tamwil (BMT). Karena kurangnya informasi membuat masyarakat kurang tahu bagaimana keuntungan yang akan diperoleh jika menjadi nasabah atau pengguna Baitul Maal Wa Tamwil (BMT). Apalagi di kecamatan Bojong Kabupaten Pekalongan terlihat masyarakatnya banyak yang memiliki usaha sehingga hal tersebut menjadi peluang besar untuk mempromosikannya agar masyarakat di daerah tersebut dapat tertarik dan berminat untuk menjadi nasabah atau menggunakan Baitul Maal Wa Tamwil (BMT). 


\section{DAFTAR PUSTAKA}

Ali, Mahmudi. 2015.Pengaruh Kualitas Produk Tabungan Dan Kualitas Pelayanan Terhadap Minat Menabung Di Bmt Tumang Cabang Salatiga. Skripsi. IAIN Salatiga.

Malayu, Hasibuan. 2009. Manajemen Dasar Pengertian dan Masalah. Jakarta: PT Bumi Aksara.

Nur, Ety Lestri. 2014. "Analisis Hukum Islam Terhadap Prakterk Ziyadah di BMT Koperasi Pondok Pesantren An-Nawawi Purworejo". Jakarta: Pinbuk.

Philip Kotler. 2004. Manajemen Pemasaran Jilid 1terj. Bob Sabran.Jakarta: PT. Indeks

Saeful, M. Hartanto. 2015. Pengaruh Mutu Pelayanan Terhadap Tingkat Kepuasan Nasabah di Bmt Al Ijtihad Pabelan. Skripsi. IAIN Salatiga.

Sofjan Assauri. 2013. Strategi Marketing: Sustaining Lifetime Customer Value. Jakarta: PT Raja Grafindo Persada.

Sudarsono, Heri. 2003. Bank dan Lembaga Keuangan Syariah. Yogyakarta: Ekonosia. 